\title{
SUPPLEMENT
}

\section{The elusive orthopaedic senior house officer}

\author{
JOHN WOODYARD
}

If there is one topic that interests orthopaedic surgeons it is how to recruit senior house officers. Last winter we finally overcame a natural reluctance to admit that we could not fill our posts with satisfactory junior doctors and found, of course, that most districts had exactly the same experience.

A survey in the West Midlands showed that out of 80 posts for orthopaedic senior house officers, many were filled by transient locums and 11 were totally unfilled. A survey in August, five months later, showed that the position was virtually unchanged. Personnel departments admit that orthopaedics is the least popular specialty, and the response to $B M \mathcal{F}$ advertisements fills only $20-40 \%$ of all the jobs so expensively advertised. Whatever else, it provides a topic of conversation whenever two or three gather together in the name of orthopaedics.

Why has this happened and can anything be done? There seem to be four main reasons - changes in the immigration and registration rules, too little interest in orthopaedics, too many unwanted senior house officer posts, and the attractions of general practice.

The final effects of the five year limited registration and the more recent four year immigration rule on doctors who do not come from the European Community are complex and difficult to assess accurately. I suppose they will be a disincentive to postgraduate work in the United Kingdom, and figures from the General Medical Council do seem to show a slight reduction in the number of doctors applying for limited registration. What is more important perhaps is the drop in the number of doctors actually holding limited registration from 5600 to 4600 in the two years to 1 January 1986 . The crucial figure will be the January 1987 figure-will it have dropped by a further 500 ? The overseas doctors with limited registration are those who are doing senior house officer posts, and a drop of 1000 already represents five doctors fewer per district looking for work.

Innes Williams estimated that by 1990 there would be roughly 2000 fewer overseas doctors than in 1985-the figures are confusing but it seems a reasonable guess.'

Few British graduates have ever been interested in orthopaedics in the past and few are interested now. Health Trends shows that surgery in general and orthopaedics in particular may have interested enough to fill future consultant posts, but the number of the 1983 graduates who were surveyed and put it as their first choice of career would fill no more than a fraction of our 690 orthopaedic senior house officer posts. ${ }^{2}$

General practice was the first choice of career of $45 \%$ of the 3160 doctors who qualified in 1983. Fourteen per cent put medicine as their first choice and $12 \%$ put surgery. When the surgery choice is broken down $6.1 \%$ chose general surgery, $1.7 \%$ ophthalmology, and $1.6 \%$ orthopaedics. The $1.6 \%$ of the graduates putting

Stafford District General Hospital, Stafford ST16 3SA

JOHN WOODYARD, MB, FRCS, consultant orthopaedic surgeon orthopaedics as first choice of career represents 52 doctors, two or three of them women, illustrating the almost total lack of interest of women doctors in orthopaedics (table I).

TABLE I-Doctors in orthopaedics, 1984

\begin{tabular}{lcc}
\hline & Women & Men \\
\hline Consultant & 3 & 676 \\
Senior registrar & 3 & 125 \\
Registrar & 10 & 369 \\
Senior house officer & 65 & 622 \\
\hline
\end{tabular}

A brief personal survey of local young doctors was undertaken to try to discover the reason for the lack of popularity of orthopaedics. Was it that undergraduate teaching put people off or was it simply the inherent nature of the subject?

\section{Quality of teaching criticised}

Graduates seemed reasonably satisfied with the amount of their medical school teaching, but a quarter thought that the quality of teaching was poor. This level of dissatisfaction, of course, may be common to all disciplines but certainly gives no grounds for complacency in our medical schools. "Boring clinical problems" are among the principal "put offs" in orthopaedics, both as a student and for a career. Other deterrents to a hospital career in orthopaedics were the hospital career structure, length of training, and intense competition - though these apply to almost all clinical hospital careers. The brute strength occasionally needed in the orthopaedic operating theatre was mainly and unavoidably a deterrent to orthopaedics for women.

What has seldom been considered in trying to fill our training posts with British graduates is that though the number of such posts has expanded enormously in the past 20-25 years the number of graduates has only roughly doubled and more of these graduates are women $(37 \%)$, who, as we see, are hardly interested in surgery and least of all in orthopaedics.

Whatever the position in other specialties the orthopaedic figures show quite clearly how we have been able to expand the senior house officer grade only by using overseas doctors, because British graduates just have not been interested in filling these posts, many of them without an obvious future (table II). There have been plenty of graduates able to fill consultant posts because of the small numbers. Indeed, had British graduates been willing to fill all our senior house officer and registrar posts the platoons of overqualified registrars applying for every job now going would have been in company or battalion strength. Now the government has recklessly cut the supply of overseas doctors and has quite predictably (or so one would have thought) produced a shortfall of surgical senior 
house officers that is causing hardship to innocent people on ever lengthening waiting lists for elective orthopaedic surgery.

This brings me to the unpopular question: How many senior house officers are needed in orthopaedics and what are they needed for?

The recent government document Hospital Medical Staffing: Achieving a Balance vaguely recommends 50 senior house officers more per region over the next 10 years in different specialties. ${ }^{3}$

TABLE II-Senior house officer posts and graduates

\begin{tabular}{lccc}
\hline & 1963 & 1984 & $\begin{array}{c}\text { Age increase } \\
(\%)\end{array}$ \\
\hline $\begin{array}{l}\text { No of graduates } \\
\begin{array}{l}\text { No of orthopaedic senior } \\
\text { house officer posts (wte) }\end{array}\end{array}$ & 1844 & 3400 & 85 \\
\hline
\end{tabular}

wte $=$ whole time equivalent.

Unfortunately, the real needs are quite different according to some recent painstaking work in the West Midlands; it prompts doubt as to the validity and sense of the document's other projections and advice.

In the West Midlands there are about 345 surgical senior house officer posts (all surgical specialties excluding obstetrics and gynaecology), of which roughly 150 are needed for training future consultants and general practitioners and roughly 190 are therefore surplus to these requirements; they provide a necessary service but are not needed for training.

\section{Bizarre picture}

The picture in orthopaedics is even more bizarre. Allowing seven years' total orthopaedic training, of which six months as a senior house officer is adequate, we need six senior house officer posts to supply the expected annual average of six consultant vacancies a year: we have 80 senior house officer posts. While the number can be increased by doubling the time required in the grade and by admitting that some posts are needed for accident and emergency and general surgical training, it is obvious that we have an enormous excess of posts if considered purely in terms of those necessary for training future British consultants.

What is the remedy? The short term answer would be to relax temporarily the immigration and limited registration rules and to lengthen preregistration to two years, but both these measures would need considerable and probably unavailable political courage.

More long term solutions to the problems include the use of sponsored overseas doctor schemes and the more extensive use of non-medical auxiliaries-resuscitation teams and operation assistants, for example.

Can we learn from other countries? How do they deal with this problem? Their methods may not be practical-for example, they have a greater reliance on private practice-but at least it might be worth making some comparisons.

The new permanent grade as proposed in Achieving $a$ Balance has nothing to offer in replacing senior house officers though it could help a lot in replacing registrars, who are equally likely to be disappearing from the scene, though for rather different reasons than those affecting senior house officers.

A major reorganisation of methods of medical work is overdue. In all surgical specialties we need to distinguish between staff requirements for elective surgery (often modest requirements) and the need to provide a three member team to deal with emergencies. The fact that some consultants work with only one assistant should not blind us to the fact that pairs of medically trained hands are needed at the moment, though again paramedical staff could be trained to do some of the "medical" work in managing both medical and surgical emergencies and in particular to assist in the operating theatre.

This raises the question of whether we need specialised surgical house officers. The ideal organisation-of surgical junior posts before specialisation in orthopaedics does not have to include a year as orthopaedic senior house officer-too much of that year is spent on the end of a retractor. Perhaps what is really needed is an apprenticeship in surgery, including some of the specialties, mainly in emergency and ward duties. This would leave clinics and specialised elective surgery mainly in the hands of specialists and non-medical technical staff. As quite a few orthopaedic consultants were never senior house officers it suggests that these posts exist principally to provide some basic help to the consultant to relieve him of some ward chores and deal with casualties; these posts exemplify the essential conflict between the National Health Service's needs for medical services and the future specialist's need for training.

\section{Need to separate training and service}

Until we separate training and service and accept the serious implications any debate about the future medical staffing of our hospitals and especially surgical staffing will be totally sterile and the present nonsense, now 40 years old, will continue.

We may be thankful that the NHS Management Board has not yet reorganised our ways of work for us. Sober reflection should compel us to take the present opportunity to suggest reform ourselves. This may mean thinking the previously unthinkable. The clock cannot be put back, and competent British senior house officers are always going to be scarce. We need to find a substitute for the surgical senior house officer slave. Lengthening preregistration to two years and suitably amending regulations for higher professional training seem the easiest options.

\section{References}

Williams DI. (Nerseas doctors and the staffing structure of hospitals. Br Med $\mathcal{Y}$ 1985;291:873-6.

2 Ellin DJ, Parkhouse HF, Parkhouse J. Career preferences of doctors qualifying in the United Ellin DJ, Parkhouse HF, Parkhouse J. Career prefer
Kingdom in 1983. Health Trends 1986;18:59-63.

3 Department of Health and Social Security, Joint Consultants Committee, chairmen of regional health authorities. Hospital medical staffing: achieving a balance. London: DHSS, 1986.

\section{YEARS AGO}

\section{Doctors and the Health Service}

SIR,-I was rather astonished in reading an article on doctors and the health service, by Mr. A. Wilfrid Adams (Supplement, May 4, p. 241), to find the phrase, "The government allots up to 3,500 patients per doctor." I am not quite sure what kind of world $\mathrm{Mr}$. Adams is living in if he really does believe that any government has power under the National Health Service to allot patients to a doctor. It is presumably for the doctor himself to secure the patients. I would, however, agree that there is a need for a reduction in the existing lists and I would very much hope that out of the current discussions on doctors' remuneration some reduction can be achieved, but, after all, this is very largely a matter for the profession itself. If they insist upon a flat rate increase in their pay there would be little encouragement to doctors to reduce the size of their lists.

Mr. Adams also refers in this article to the load of work on general practitioners. I feel it would be of very real interest to know rather more about the effect of the National Health Service on general practitioners as a whole so far as their working load is concerned. Possibly the British Medical Association have information from some of the inquiries they have carried out that would let us know, for example, whether there has been on the average any increase in the number of calls made by a patient upon a doctor. As a layman I do find it rather difficult to relate many doctors' complaints about the number of calls made upon them by patients with their continual and very proper insistence that patients should not hesitate to get in touch with them at an early stage of any illness. - I am, etc.

London, S.W.1

ARThUR BLenkinsop, M.P. 